\title{
The determinants of box office performance in the film industry revisited
}

\author{
N.A. Pangarker and E.v.d.M. Smit* \\ University of Stellenbosch Business School, \\ PO Box 610, Bellville 7535, Republic of South Africa \\ eon.smit@usb.ac.za
}

\begin{abstract}
The film industry is a significant player in the global economy. It calls for significant up-front investments with the result that analysts, studios and investors alike are interested in predicting box office success as part of financial risk management.

This study utilises global box office revenue in assessing the effects of eight explanatory variables, identified from previous studies, in the explanation of revenue. Nearly three decades after the seminal study the extension of the original methodology to global rather than USA data, still confirms production cost, releases by major studios, award nominations and sequels to successful films as the key drivers of global box office revenue. The evidence further suggests that in the modern global context, the film genre, the release date around holidays and positive critical reviews play a less significant role than in the original investigation.
\end{abstract}

*To whom all correspondence should be addressed.

\section{Introduction}

The film industry is a significant contributor to the world economy. Worldwide box office revenue for all films released during 2010 was estimated at $\$ 31.8$ billion. In the United States of America (USA) alone, the industry is a major employer, supporting over 2.2 million jobs, and paying over $\$ 137$ billion in total wages in 2009 . Direct jobs in the film industry in the USA generated $\$ 40.5$ billion in wages, with an average salary $26 \%$ higher than the national average. Jobs in the core business of production, marketing, manufacturing and distribution of films were estimated at 272000 in 2009 (Motion Picture Association of America (MPAA), 2011).

From as early as the mid-1960's analysts, studios, and investors alike have been researching which variables contribute to the commercial success of films. The body of knowledge regarding the significance and importance of variables which influence box office revenue, is still maturing. This article continues the quest by developing a model to predict the financial success of films by examining the significance of various explanatory variables in forecasting global box office revenue of films. ${ }^{1}$

It is unique insofar, to the authors' knowledge, it is the first attempt at utilising global box office revenues for films as a

\footnotetext{
${ }^{1}$ The words "film", "feature film", "movie" and "motion picture" are used interchangeably. This work is based on the research supported in part by the National Research Foundation of South Africa (Grant specific unique reference number (UID) 85617;
}

proxy for the success of films. All previous studies sourced have used domestic box office data for the USA market only.

The article is structured as follows. Section 2 consists of a literature review focusing on existing research examining which variables, if any, determine the box office success of films. Section 3 sets out the research methodology by defining the sample, the dependent variables, the independent variables and the statistical model. Section 4 contains a discussion on the key research findings informed and relate the findings to previous literature on the subject, whereafter Section 5 concludes with a summary of the main findings, recommendations and conclusions.

\section{Literature review}

A survey of the research on which factors influence the success of films and their measurement reveals that the majority of studies to date were based on data derived from the performance of films produced and released theatrically in the USA.

The first multiple regression model used to predict the financial success of films was developed by Litman (1983) who was inspired by the statement of Jack Valenti, former president of the MPAA, quoted as saying: "no one, absolutely no one can tell you what a film is going to do in the marketplace". Litman was set on testing this conventional wisdom. He referred to three crucial decision making areas that seemed important in determining the success of a film. The three areas were the creative sphere, the scheduling and release pattern, and the marketing effort. Factors which he considered important in the creative sphere included the story, which he felt had to be genuine, 
believable, and timely. One may judge by the films released in recent years, that the genuine and believable attributes are not that important anymore. An examination of the top ten highest grossing films ever released indicated that nine were science-fiction, animation, or superhero films. The highest grossing film to date is Avatar, which grossed \$2,7 billion and is a science fiction film. The only exception on the highest grossing film list was Titanic, based on a true story, that grossed \$1,8 billion (Box Office Mojo, 2012).

Other factors which Litman (1983) viewed as important in the creative sphere were the cast, director, production budget, and rating. In the scheduling and release phase, Litman viewed it important for an independent producer to engage a major distributor for a film release, because they have greater bargaining power, more substantial financial resources, preferential access to theatres, reputations of delivering high quality products, and extensive distribution networks. Litman also stated that there were periods of peak audience for film attendance and that these periods were around Christmas and New Year, summer, and Easter. Evidence from the Indian film industry, which produces the highest number of films annually, indicate that there may be truth in the seasonality phenomenon as film releases in India are often concentrated around certain holidays.

Litman (1983) highlighted the media campaign as a key component of the marketing effort. He argued that after the film was released, word-of-mouth replaced the advertising campaign, and if word-of-mouth was negative, additional advertising would be totally ineffective. He introduced the role of critics and their role as influencers and explored the role of Academy Awards and their ability to motivate audiences to watch films.

To test the theories of film success, Litman set up a multiple regression model with dependent variable, as a proxy for revenue, theatrical rentals accruing to the distributor. The first independent variables included were binary variables representing genre. The genres were science-fiction, drama, action-adventure, comedy and musical. The second set of independent variables were binaries for ratings by the MPAA. The third measure of content involved a binary variable for whether there was any superstar in the cast. The fourth independent variable was a variable for the production cost of each film. As expected, production costs were the most difficult to find, as even today production costs are not entirely accurately reported by the industry. The production costs were also adjusted for inflation. The fifth independent variable he used was a binary variable for whether the film was distributed by a major company or an independent distributor. The sixth independent variables were binary variables for what he believed to be the three peak release periods namely, Christmas, Easter, and summer. Two binary variables were included for an Academy Award nomination and an Academy Award won. The last independent variable used by Litman attempted to capture the impact of critics' reviews. He used the star rating assigned by a daily newspaper as a measure of capturing this factor. A higher star rating signalled a higher critical acclaim.
Litman ran several tests to eliminate those independent variables that had no significant impact on the dependent variable. The variables that were eliminated included ratings, the superstar factor and the binary variables for summer and Easter releases. All genres except science fiction and horror were eliminated as insignificant.

Production costs were positively correlated with rentals and the power of critics' reviews was also significant. Science fiction and horror films were extremely popular and so were films distributed by major distributors. The Christmas release variable, Academy Award nominations and Academy Awards won were all significant. Litman's ground-breaking research laid the foundation for many studies that followed over the next two decades.

De Vany and Walls (1999) embarked on a study using a sample of over 2000 films. They proposed that filmmakers operated under vague and uncertain knowledge of probabilities of outcomes that "no one knows anything". According to them, the mean box office revenue was dominated by a few blockbuster films and the probability distribution of box office outcomes had infinite variance. The distribution of box office revenue according to them was a member of the class of distributions known as Levy stable distributions and film revenues diverged over all possible outcomes. De Vany and Walls (1999) suggested that the average of motion picture revenues depended almost entirely on a few extreme revenue outcomes in the upper tail whose chances were extremely small. They were steadfast in their opinion that there were no formulas for success in Hollywood. They contended that producers could make strategic choices in booking screens, budgets, and cast that could improve their chance of success, but after a film opened, the audience decided its fate. They stated that the exchange of information among a large number of individuals (the audience) interacting personally, unleashed a dynamic that was complex and unpredictable and even an expensive marketing campaign could not direct that information cascade. That assertion may be valid, especially in current circumstances where social networking has become a critically important and extremely fast medium of disseminating information. De Vany and Walls (1999) were of the view that:

films were complex products that were difficult to make well;

nobody knew whether they would like a film until they had seen it;

films were once-off unique products and their shelf-lives were only a few weeks;

films entered and exited the market on a continuing basis; and

most films only had a week or two to capture the audience's imagination.

De Vany and Walls (1999) modelled film revenues as probability distributions. Amongst the variables which they considered as probability altering variables were sequels, genres, ratings, stars, budgets and opening screens. They also considered individual stars and how much power they had to move the box office revenue probability distribution toward more favourable outcomes. 
Table 1: Highest grossing films released worldwide

\begin{tabular}{l|l|c|c}
\hline \multicolumn{1}{c|}{ No } & \multicolumn{1}{c|}{ Title } & $\begin{array}{c}\text { Gross Revenue in } \\
\text { US\$ billion }\end{array}$ & Year of Release \\
\hline 1 & Avatar & 2,782 & 2009 \\
\hline 2 & Titanic & 1,843 & 1997 \\
\hline 3 & Harry Potter and the Deathly Hallows - Part 2 & 1,328 & 2011 \\
\hline 4 & Transformers: Dark of the moon & 1,123 & 2011 \\
\hline 5 & The Lord of the Rings: The Return of the King & 1,119 & 2003 \\
\hline 6 & Pirates of the Caribbean: Dead Man's Chest & 1,066 & 2006 \\
\hline 7 & Toy Story 3 & 1,063 & 2010 \\
\hline 8 & Pirates of the Caribbean: On Stranger Tides & 1,043 & 2011 \\
\hline 9 & Alice in Wonderland & 1,024 & 2010 \\
\hline 10 & The Dark Night & 1,001 & 2008 \\
\hline
\end{tabular}

Source: Box Office Mojo (2012)

The mean revenue in their sample was $\$ 17$ million, and this was much larger than the median of $\$ 6.9$ million. The mean was in the $71^{\text {st }}$ percentile of the revenue distribution, an indication of an extremely rightward skew. Films without stars had a median gross revenue of $\$ 20.9$ million while films with stars had a median gross revenue of about $\$ 38.2$ million. Their results showed that the distribution of production costs was highly skewed, but not as skewed as the revenue distribution. Their mean production cost was $\$ 11.8$ million and this was in the $62^{\text {nd }}$ percentile. Median production costs varied from $\$ 1.9$ million for documentaries to $\$ 17.4$ million for science-fiction films. Films without stars had a median production cost of $\$ 9.7$ million compared to films with stars that had a median production cost of $\$ 22.8$ million. De Vany and Walls (1999:298) deduced that large budgets and big stars could create the biggest of flops, whilst smaller budget films with no star presence could become big successes. Most of the films in their sample were unprofitable.

Their paper attempted to explain star power, and found that most films with very large gross returns, in fact had no stars, had low revenues and tiny budgets. They proposed that one of the ways that star power might work was by virtue of getting it released on many screens at the opening, thus increasing initial revenue. Another way they suggested that stars may have had a positive impact on a film was by bringing a level of performance to the film that raised it above the ordinary. They found only 19 stars to have a significant impact on the hit probability. Their research confirmed that no star could guarantee a hit, and that they all faced infinite variance of the Levy distribution, so they each had a measure of risk associated with them. Stars also exhibited sizeable standard errors of their estimated hit coefficients. Stars like Michelle Pfeiffer, Jodie Foster, and Sandra Bullock had high standard errors, implying that their positive impact was more variable. The smallest standard error was attributed to Tom Hanks (0.357), though his hit impact was smaller than Tom Cruise whose estimated hit coefficient was 2.011. According to them stars only increased the odds of favourable events that were highly improbable.

De Vany and Walls (2002 \& 2004) further asserted that the studio model of risk management, whereby studios need to draw a film project out of so many available, lacked foundation in theory and evidence. They claimed that in such highly competitive situations, experience and learning, which were predictors of success on average, were not closely related to outcomes because success depended on something different - getting an extreme draw in a small sample. They were of the opinion that one cannot under those circumstances, extrapolate success into the future and that the film business encouraged selective learning based on extreme events. They also asserted that studios attributed success to ability and failure to bad luck, and that affected the way they approached risk in the industry.

De Vany and Walls (1999:314) stated that past success gave studio executives an "illusion of control", but reiterated that one was unable to link success to causal factors and viewed the film industry as having complicated stochastic dynamics, where there was no simple form of causality. They stated that the probability that a film would reach an extreme outcome in the upper tail, which was required for it to be profitable, was small. They concluded that forecasts were meaningless because the possibilities did not converge on a mean; they diverged over the entire outcome space with an infinite variance and they suggested that the strategy of choosing a portfolio of films could be the preferred method, rather than selecting individual film projects.

Sawhney and Eliashberg (1996) developed a parsimonious model for forecasting gross box-office revenue based on early box office data. Their model was intended to assist film exhibitors (theatres) in managing their exhibition capacity and in negotiating exhibition licence agreements with the distributors by allowing them to predict box-office potential based on early box-office results. They drew upon queuing theory framework to conceptualise the customer's film adoption process in two steps, namely the "time to decide" to see the new film, and the "time to act" on the adoption decision. These two steps were modelled as two independent stochastic processes. They made some important observations about the characteristics of the film industry including that:

most revenues are derived from new films;

the shelf life of a typical film was less than 15 weeks in a theatre release;

hundreds of films were launched every year;

demand for a new film was highly uncertain; and it was difficult for a consumer to evaluate a film unless they have actually seen it. 
Their model had the ability to forecast box office attendance with little or no revenue data. This was done by using an adaptive approach where the model was updated as data becomes available after one week, two weeks, and three weeks of release. Their approach to generating sales forecasts with no data was conducted by performing a metaanalysis of parameter estimates of related and similar products. In this process, the model parameters for several existing products whose sales histories were available were related to the attributes of the product which revenue they were trying to forecast. This relationship was used to predict the parameter estimates and consequently the sales for the new product. The film industry afforded a unique opportunity to run such an analysis since historic sales data for most films released were publicly available. By their own admission they stated that their model had limitations, which if relaxed, could refine the accuracy of the model. These two limitations were that the "time to decide" and "time to act" processes were independent, and that adoption process parameters were stationary. By relaxing these, one would require much more data which would make the model much more complex than the existing one. The advantage of conducting a cross sectional analysis as they did was that the life cycle of a film was relatively short, which eliminated the need to account for major changes in macroeconomic factors and consumer tastes, thus maintaining the accuracy of such analysis.

Ravid (1999) explored the role of stars and other potential informational signals in the film industry. He presented two alternative explanations for the roles of stars in films. His first hypothesis maintained that stars essentially captured most of their value added in a film. Essentially this meant that star salaries reflected their market value. According to Ravid, this "rent capture hypothesis" indicated that stars very quickly adjusted their fees to reflect their value. He cited the example that John Travolta who earned only $\$ 150000$ for his role in the film Pulp Fiction, had increased his fee to $\$ 10$ million after the success of that film. According to film industry website thenumbers.com, Pulp Fiction was produced at a cost of $\$ 8$ million and its worldwide box office revenue amounted to $\$ 212$ million (The Numbers, 2012). Ravid also cited the example of Alicia Silverstone, who earned $\$ 250000$ for her role in the film Clueless, increasing her fee to $\$ 5$ million immediately thereafter.

His second hypothesis states that informed insiders signal project quality by hiring expensive stars. His reasoning for this was based on the role of studio executives whose careers depended on the success of the films they produced. With a very high probability of being fired if a film was unsuccessful, a commitment to a star could be a high-risk proposition for a studio executive with a risk averse profile. An early commitment to such a star could act as a signalling device about the quality of the project to the studio or outside financiers. The executive would be interested in the current effect of the signal because his/her current compensation would probably be linked to the current project he or she was involved with.

Ravid tested these hypothesis using a sample of 200 films released between 1991 and early 1993. A comparison of the means in his study suggested that films with stars brought in higher revenue. The results of his regression models showed that the most significant independent variable was the budget. This meant that films that were more expensive generated higher revenue. The other significant variable was the number of reviews the film received. It is interesting to note that when he increased the number of independent variables in his regression model, stars were not correlated with revenues any more, in fact the coefficients became negative. Sequels and highly visible films also contributed to revenues. Total revenue was also found to increase if the film was rated family friendly (i.e. G or PG). Ravid is one of the few authors who also used rate of return as a dependent variable, as opposed to just revenue. His results indicated that big budgets did not contribute to profitability, and in fact contributed to losses (the correlation coefficient was negative).

The research by the authors reviewed above, collectively present the foundations of research attempting to explain the determinants of box office revenue. Other authors have contributed extensions to the landmark research presented above. Smith and Smith (1986) analysed a sample of films produced from the 1950's to the 1970's. They found that the total number of awards a film received influenced the revenue of a film. This is consistent with the study by Nelson, Donahue, Waldman and Wheaton (2001) who quantified the value of an Academy Award nomination. They estimated an Academy Award nomination could add $\$ 4.8$ million to the box office revenue of a film whilst an Academy Award won could add $\$ 12$ million to box office revenue. This is consistent with Litman (1983) who estimated the value of an Academy Award nomination of \$7.34 million and the value of an Academy Award won to be $\$ 16$ million. Dodds and Holbrook (1988) examined the impact of the Academy Awards before and after the awards ceremony. They found the value of a best actor nomination to be $\$ 6.5$ million, best actress nomination to be $\$ 7$ million, and best picture nomination to be $\$ 7.9$ million. Post the awards they found the value of a best actor award won to be $\$ 8.3$ million and the value of a best picture award to be $\$ 27$ million. Smith and Smith (1986) stated that the power of the Academy Award variable was not constant and could change over time and in fact could have a positive or negative effect on the financial results of a film depending on the time period. One may conclude from the research above that an Academy Award nomination or won would have an impact on the box office revenue of a film.

Eliashberg and Shugan (1997) studied the roles of critics and critics' reviews. They identified the role of a critic as one of influencer or predictor. Their results indicated that a critic could influence the box office success of a film. According to them, the influencer role in particular would have an impact on box office revenue. The predictor role was possible but not as statistically significant as the influencer role. According to Reinstein and Snyder (2000) only a few critics had the power to influence consumer demand and thereby box office revenue. Wallace, Seigerman, and Holbrook (1993) stated that a highly rated film would continue to gain at the box office for every extra positive review it received. 
Austin (1984) studied MPAA ratings with the hope of finding a correlation between ratings and film attendance. He found no significant relationship between film ratings and audience attendance. Prag and Casavant (1994) found that PG-13 and R rated films did not perform better at the box office.

A number of studies revolved around trying to find a relationship between genre and box office success. Anast (1967) found a negative relationship between action adventure films and revenue and a positive one between violence and eroticism and revenue. Litman (1983), as mentioned earlier, found a positive relationship for science fiction films and revenue. In Sawnhey and Eliashberg's (1996) research based on "time to act" and "time to decide", they found with the drama genre, audiences' reaction time was slower and with the action genre their time to react was faster. Prag and Casavant (1994) found a negative relationship between the drama genre and revenue. Neelamegham and Chinatagunta (1999) used a Bayesian model to predict film attendance in domestic and international markets. They found that the thriller genre was most popular and romance was least popular. As these studies were conducted using sample data over various time periods ranging over many decades, it would not be unexpected to find a changing relationship between genre and revenue, as audience tastes would have changed over the decades.

Some of the studies referred to the seasonality and success of films. Both Litman (1983) and Einav (2001) found a positive correlation between films released over Christmas and revenue. Sochay (1994) found evidence that summer months (in the northern hemisphere) were better to release films, contrary to Litman's view. Einav also presented evidence that summer releases had a positive correlation with revenue. Radas and Shugan (1998) found that peak season releases performed better at the box office.

A study by Terry, Butler and De'Armond (2005) used a sample of 505 films released during the period $2001-2003$. The study was unique because their data set used a cross section of films, and unlike other studies was not limited to data of high profile films only. They filtered their universal sample down to films that opened in 25 or more theatres. This eliminated less than 80 films from their universal sample. Their model used domestic gross box office revenue as the dependent variable and concluded that the critical approval variable was positive and statistically significant and that a 10 per cent increase in critical approval would add $\$ 7$ million to box office revenue. The holiday variable in their model was not statistically significant. Their finding around a holiday release was inconsistent with other studies. They attribute this unexpected finding to the fact that certain major blockbuster films in their data set were released a few weeks before the traditional holiday period. The $\mathrm{R}$ rating variable was found to be negative and statistically significant. The negative coefficient was $\$ 12.5$ million. Terry et al. (1995) are in the minority of researchers who included a variable indicating whether the film was a sequel. The coefficient for sequel was a positive $\$ 36$ million. The action genre variable was positive in their model but the children's genre was negative. According to their model, the
Academy Award nomination was significant and worth more than \$6 million per nomination. The number of theatres in which the film was released was positive and statistically significant thus films released in more theatres could be expected to perform better at the box office. The budget variable in their model was positive and statistically significant implying that films with big budgets performed better at the box office. One of the avenues for future research which they identified was to expand the definition of worldwide success by focusing on global box office revenue.

From the literature review it can be concluded that there are no final answers when determining which factors contribute to box office success. The various models have yielded contradictory evidence depending on the attributes of the datasets used. For ease of reference, the literature leads to the following hypotheses regarding variables impacting on box office success:

- $\quad$ certain film genres;

- $\quad$ MPAA ratings;

- $\quad$ the size of the budget;

- major studio involvement;

- Academy Award nominations or awards;

- $\quad$ timing of release; and

- critics' reviews

\section{Research methodology}

\section{Sampling}

The current research was based on the work of Litman (1983), also using a multiple regression model. What makes this model unique is that, where other studies used domestic box office sales (as reported for the USA region only) as the dependent variable, this model used global box office revenue as the dependent variable. It was identified in the study of Terry et al. (2005) as an important avenue for future research. The current study used more recent data in an effort to determine whether the independent variables selected possessed any explanatory power with respect to forecasting international box office revenue for films released in the USA and abroad over the two year period 2009 to 2010.

The primary data used in this study were extracted from the OpusData database. OpusData is a subscription-based service that collects, and makes available, data on the USA film industry. The data population started with an extraction of all films released in the US during the years 2009 and 2010. In 2009, 618 films were released in the US and in 2010, 645 films were released giving a total population size of 1263 films. The sample was paired down to eliminate missing data, particularly budget data, also referred to as production cost. The data was then further filtered to exclude films that were not released in the international market. The uniqueness of this study is that it used global box office revenue as the dependent variable. Foreign language films were also eliminated. The final sample contained a total of 289 films. 
Although certain studies used data of only successful films or the top 100 films, this sample contained both financially successful and unsuccessful films. Information on critics and Academy Awards were not available in the OpusData database. The website metacritic.com was used to retrieve critic information (Metracritic, 2012). Metacritic aggregates reviews from the most influential and recognised film critics, which it then combines in a single score called a metascore. The information on Academy Awards was retrieved from the AMPAS database website (AMPAS, 2012) and manually added to the dataset for each film.

\section{The data}

\section{Dependent variable}

The dependent variable used in this model is the global box office revenue earned by each film expressed in US Dollars. This data was extracted from OpusData which had a separate total for domestic (US) and international box office for each film. The two totals were aggregated for each film and generated a total value for global box office revenue. These values were not adjusted for inflation because:

the period for which data was collected was only two years (2009-2010);

films ran at the box office for less than three months; and

the international box office includes earnings from countries outside of the US, and the actual value per country was not available making inflation adjustments difficult.

\section{Independent variables}

\section{Production cost}

The first independent variable is a variable for the production cost of the film. This was obtained from the OpusData database. Where the production cost was not available, the film was excluded from the sample. The production cost was quoted in US Dollars. The production cost did not include advertising and marketing costs as these are commonly incurred by the releasing studio and not by the producers of the film.

\section{Genre}

The assumption was made that action/adventure and drama genres are the most popular. Each film extracted from OpusData was classified according to genre. In the sample, 69 films were in the action/adventure genre and 81 were in the drama genre. Two separate variables were created for genre. A dummy binary variable with the value of 1 was assigned to action adventure and a dummy binary variable of 1 was assigned to the drama genre.

\section{Release company}

Prior research by Litman (1983) indicated that films released by a major company (also referred to as a major studio or major distributor) performed better at the box office. A dummy binary variable with the value of 1 was assigned to every release by a major company.

\section{Holiday release}

A holiday release was defined as a film released over Christmas, Easter, or the summer holidays (in the northern hemisphere). It was expected that films released over holiday periods would perform better at the box office. Each film's release date was extracted from the OpusData database. A dummy binary variable was then assigned to the release period based on whether it fell in the holiday period. A value of 1 was assigned to a holiday release.

\section{Academy Award}

The number of Academy Award nominations a film received was extracted from the AMPAS awards database and manually added to the sample data. Each film in the sample was thus assigned a numerical value, ranging from 0 for the films in the sample that had no nominations to 12 for the film The King's Speech thatreceived 12 nominations, the highest number of nominations in the sample.

\section{Critics' rating}

Critics' rating was the approval rating assigned to a film by a group of critics. This data was retrieved from Metracritic.com. Metacritic aggregates all reviews by professional film critics into a single number ranging from 0 to 100 . The higher the number, the more positive reviews a film received. The highest rating in the sample was 95 for the film The Social Network, and the lowest rating was 18 for The Nutcracker in 3D.

\section{Sequel}

Very few studies have looked at the effect of a film being a sequel in a series of films. It was assumed that sequels could perform well at the box office as consumers would be familiar with what to expect, having watched a previous film in the series. The sequel data was retrieved from the OpusData database. A dummy binary variable of 1 was assigned if a film was a sequel.

\section{The model}

The empirical model used to examine the determinants of global box office revenue for films is specified as:

$$
\begin{aligned}
& \text { Revenue }=\beta_{0}+\beta_{1} \text { ProductionCost }_{\mathrm{i}}+\beta_{2} \text { Action }_{\mathrm{i}}+ \\
& \beta_{3} \text { Drama }_{\mathrm{i}}+\beta_{4} \text { Major }_{\mathrm{i}}+\beta_{5} \text { Holiday }_{\mathrm{i}}+\beta_{6} \text { Award }_{\mathrm{i}}+ \\
& \beta_{7} \text { Critic }_{\mathrm{i}}+\beta_{8} \text { Sequel }_{\mathrm{i}}+\mathrm{e}_{\mathrm{i}}
\end{aligned}
$$

where

Revenue is global box office revenue earned by a film in US Dollars

ProductionCost is the total production budget in US Dollars Action is the dummy variable indicating an action genre film

Drama is the dummy variable indicating a drama genre film Major is the dummy variable indicating a release by a major company

Holiday is the dummy variable indicating a release during the holiday period

Award is the number of Academy Award nominations a film received

Critic is the approval rating for a film 
Sequel is the dummy variable indicating the film is a sequel to a previous release

e indicates the regression error

The equation was estimated using a stepwise procedure.

\section{Findings}

\section{Data analysis}

Average global box office revenue was $\$ 154$ million, with a minimum of $\$ 117270$ for the film Freakonomics and \$2,7 billion for the film Avatar. To date Avatar was also the highest grossing film ever produced. This broad range is probably the most significant feature of the film industry. The average production cost was $\$ 52$ million, with a minimum of $\$ 1,3$ million for the film The Girlfriend
Experience and a maximum of $\$ 260$ million for the film Tangled. Action films constituted 24 per cent of all films in the sample, whilst drama films constituted 28 per cent of films in the sample. Of all the films in the sample, 63 per cent were released by a major studio, and 36 per cent were released during a holiday period. The maximum number of Award nominations received was the film The King's Speech with twelve nominations. The Average critical rating was 54 per cent with a standard deviation of 17 per cent. Of all the films in the sample, approximately ten per cent were sequels.

A simple correlation test of the correlation coefficients between the global box office revenue and the explanatory variables was conducted. The results thereof are tabulated in Table 2.

Table 2: Correlation matrix of independent and dependent variables

\begin{tabular}{|c|c|c|c|c|c|c|c|c|c|}
\hline & Ln Revenue & Ln Production Cost & Action & Drama & Major & Holiday & Award & Critic & Sequel \\
\hline Ln (Revenue) & 1,000 & & & & & & & & \\
\hline Ln (Production cost) & $0,735^{*}$ & 1,000 & & & & & & & \\
\hline Action & $0,363^{*}$ & $0,490^{*}$ & 1,000 & & & & & & \\
\hline Drama & $-0,230 *$ & $-0,285^{*}$ & $-0,349 *$ & 1,000 & & & & & \\
\hline Major & $0,485^{*}$ & $0,439 *$ & $0,194 *$ & $-0,160 *$ & 1,000 & & & & \\
\hline Holiday & $0,132 *$ & 0,104 & 0,041 & $-0,094$ & $0,152 *$ & 1,000 & & & \\
\hline Award & $0,231^{*}$ & 0,049 & 0,043 & $0,152^{*}$ & $-0,031$ & 0,087 & 1,000 & & \\
\hline Critic & $-0,023$ & $-0,204^{*}$ & 0,010 & $0,293^{*}$ & $-0,084$ & 0,019 & $0,470^{*}$ & 1,000 & \\
\hline Sequel & $0,337 *$ & 0,242 & $0,182 *$ & $-0,111$ & $0,143 *$ & 0,031 & $-0,023$ & $-0,087$ & 1,000 \\
\hline
\end{tabular}

*Significant at the 0.05 level

Table 2 shows a strong positive relationship between budget and revenue, indicated by the correlation coefficient of 0,735 . This was expected and is consistent with the findings of Litman (1983) and Terry et al. (2005). This coefficient also exhibited the greatest correlation with revenue when compared to the remainder explanatory variables. The correlation coefficient for the action genre with revenue was 0.363. This was contrary to the findings of Litman (1983) who reported a coefficient of $-0,199$, but consistent with Terry et al. (2005) who reported a positive relationship.

The correlation matrix shows a negative relationship between drama genre and revenue with a correlation coefficient of $-0,230$. This confirms the observations of Prag and Casavant (1994) that there was a negative relationship between the drama genre and revenue. The correlation coefficient between distribution by a major studio and revenue was 0,485 . This was consistent with the findings of Litman (1983). The correlation coefficient between holiday release and revenue was weakly positive. The author expected a stronger relationship between these two as all the literature indicated a positive relationship between holiday releases and revenue. The correlation coefficient between an award nomination and revenue was 0,231. This was expected as films that were nominated for Academy Awards would perform better at the box office. This finding was consistent with all the literature examined in this study. The coefficient which surprised was the one reflecting a negative relationship between critics' review and revenue. It was anticipated that this would be positive, as films that received more positive reviews were expected to perform better at the box office based on the reviews. All the literature reviewed on the subject matter indicated a positive relationship between critics' reviews and revenue.

The correlation coefficient between sequels and revenue was positive at 0,337. This was expected as audiences would be fairly familiar with a previous film in a series and therefore make a more informed decision about watching a film. Furthermore, it is expected that a producer would only embark on making a sequel if its predecessor was a hit film, and on that basis the producer would expect the sequel to perform well at the box office.

The stepwise regression results for the model presented by Equation 1 is summarised in Table 3. The model employed a $\log$ form correcting for obvious outliers that existed in the sample as a result of blockbusters. The dependent variable (revenue) and independent variable (production cost) were transformed into log form. A stepwise regression analysis was performed in an attempt to eliminate any correlated independent variables and to determine the relative explanatory power of each independent variable. 
As can be seen from the preceding results four independent variables (production cost, major, award, and sequel) exhibited a highly significant linear relationship with revenue, and four independent variables (action, drama, holiday, and critic) did not exhibit a significant linear relationship with revenue.

\section{Interpretation of the results and comparison to the literature}

\section{Production cost}

The production cost variable was positive and highly significant. Production cost was the most significant variable of the eight in the model. This variable implies that the higher the budget, the higher the revenue of a film. This is consistent with the results of Litman (1983), Ravid (1999), and Terry et al. (2005). Big budget films commonly have big name stars, special effects, large advertising budgets, which were expected to attract bigger audiences to the box office. The data set used showed that the 12 highest budget films had production costs of $\$ 200$ million and higher. Of these twelve films the lowest earner was Robin Hood that grossed $\$ 322$ million at the box office against a production cost of $\$ 200$ million. The highest earner was Avatar with $\$ 2,7$ billion at the box office against a production cost of $\$ 237$ million. Avatar was also the highest grossing film ever produced to date. Interestingly, the highest budget film in the data set was Tangled which cost $\$ 260$ million to produce, but only grossed $\$ 586$ million at the box office. This however does not imply anything about the actual profitability of the films. Though Avatar was the highest grossing film to date, its profitability which was simply calculated as total revenue as a percentage of total production cost in the absence of further detailed data, was 1
175 per cent. The film with the highest profitability in the data set was Paranormal Activity with a return of 5917 per cent. Its production cost was $\$ 3$ million and its gross revenue was $\$ 177$ million. In terms of profitability, the twelve most profitable films had an average production cost of \$20,2 million (excluding Avatar which was treated as an outlier). In directing further research, given that one is able to obtain detailed data, one may want to examine the effect of variables on actual profitability or investment return of films.

\section{Major distributor}

The results showed a statistically significant relationship between a film released by a major studio and revenue. In the data set 62 per cent of all films were released by a major studio. Of the top 20 revenue earners, only two films were not released by a major studio (The Twilight Saga: New Moon and The Twilight Saga: Eclipse). According to this model, films released by a major studio were expected to earn $\$ 11,3$ million more in revenue than films not released by a major studio. The data set also showed that of the 50 lowest revenue earners, 72 per cent were not distributed by a major studio. The result of this model is consistent with Litman (1983) who reported a strong positive relationship between a major release and revenue. Litman reported that films distributed by major studios earned $\$ 7,21$ million more than those distributed by independent studios. This result was contrary to Sombunarasin (2010) who reported that major studios had a negative effect on revenue and do not guarantee success of films. Major studios normally have bigger marketing budgets and strong distribution networks ensuring that their films reach as many screens as possible and thereby maximising revenue.

Table 3: Determinants of revenue (2009-2010)

\begin{tabular}{l|c|c|c}
\hline & Coefficients & t-value & P-value \\
\hline Intercept & 1,077 & 1,023 & 0,307 \\
\hline LN Production Cost & 0,930 & 14,682 & 0,000 \\
\hline Major distributor & 0,745 & 5,240 & 0,000 \\
\hline Award nomination & 0,209 & 5,974 & 0,000 \\
\hline Sequel to success & 0,958 & 4,603 & 0,000 \\
\hline $\mathrm{R}^{2}$ & 0,643 & & \\
\hline F-value & 127,711 & & \\
\hline Significance level & 0,000 & & \\
\hline
\end{tabular}

\section{Award nominations}

The results showed strong evidence of a significant linear relationship between award nomination and revenue. In this sample, of the top twenty highest grossing films, twelve received Academy Award nominations. Avatar received nine nominations. The film The King's Speech received twelve nominations and grossed $\$ 427$ million, the 25 th highest revenue earner in the sample. In the sample 54 films received one or more Academy Award nominations. According to the model, being nominated for an award was worth approximately $\$ 39$ million. The coefficient for the award variable implies that for every award nomination earned, the revenue should increase by about 23 per cent.

These results were consistent with those of Litman (1983), Smith and Smith (1986), Dodds and Holbrook (1998), Nelson et al. (2001) and Terry, et al. (2005). According to Litman, being nominated for an award is capable of generating significant additional business. His model estimated that being nominated for an Academy award in one of the top three categories was worth $\$ 7.34$ million in 
additional revenue. His study went further and estimated that actually winning an award was worth about $\$ 16.3$ million. Terry et al. (2005), are of the opinion that a nomination serves as a signalling device, indicating which films are viewed by industry experts as being worthy of recognition. According to their model, an Academy Award nomination was worth more than \$6 million per nomination. They, together with Litman both concur that it was not surprising, given the value of an award, that major distributors spent large amounts on advertising and campaigns before the awards in order to attract the favour of the members of the Academy. Sombunarasin (2010) also alluded to the signalling theory, particularly where a first film in a series of sequels received an award, in which case it will have a positive effect on the success on the following films in the series.

\section{Sequel to successful film}

The results showed overwhelming evidence of a significant linear relationship between sequels and revenue. The result for sequel implied that a sequel could add as much as $\$ 169$ million to box office revenue. In the sample set, 30 films were sequels. Of the twenty highest grossing films in the sample, ten were sequels, of which six were in the top ten. Of the 20 highest grossing films, fourteen were sequels. The highest grossing sequel in the sample set was Toy Story 3 which was the second highest gross earner with a total revenue of $\$ 1.064$ billion. Other significantly high earners in the sample set which were sequels were The Dark Knight (grossing $\$ 1$ billion), two in the Harry Potter series (each grossing in excess of $\$ 900$ million), Ice Age (grossing $\$ 886$ million), and Transformers (grossing $\$ 836$ million). In the sample, of the 150 lowest grossing revenues, only three were sequels.

These findings were consistent with that of Terry et al. (2005) who found a positive and statistically significant relationship between sequels and box office revenue. Most of the blockbuster films in their sample, were sequels. They concurred that the sequel was a major player in the world of motion pictures and should be included as a determinant in future research. This is also consistent with the results of Sombunarasin (2010) who had 102 sequels in her sample of 200 films. She suggests that the first sequel's box office success guarantees the success of the next sequel in the series.

\section{Action genre}

The results did not show any linear relationship between the action genre and revenue. The coefficient for action was negative. The action variable was included in the model because of the 20 highest grossing films in the data set, 15 were in the action genre. Action films made up 24 per cent of the total sample by genre. The nine highest grossing films in the data set were all in the action genre. The results of this model is consistent with Anast (1967) who also found a negative relationship between action genre films and revenue. It is however contrary to Terry et al.'s (2005) study that found a positive relationship between the action genre and revenue. The difference could be explained by a difference in audience taste over time. Terry et al.'s sample contained films released in the period $2001-2003$ and this research focussed on films released during 2009 and 2010. Furthermore, this research used total box office revenue while their study was confined to domestic box office revenue.

\section{Holiday release}

The results of this regression analysis showed that there was no linear relationship between a holiday release and revenue. In the data set however, 35 per cent of releases were during the defined holiday periods. Six of the highest grossing films in the sample set (Avatar, Toy Story 3, Harry Potter and the Half Blood Prince, Ice Age: Dawn of the Dinosaurs, Transformers: Revenge of the Fallen, and Inception) were all released during the holiday period. Of all the films grossing more than $\$ 100$ million in the sample, 63 (or 58 per cent of the sample) were actually released outside the holiday period. Some of these included Alice in Wonderland, The Dark Night, Harry Potter and the Deathly Hallows, Shrek, and Up. It is interesting to note that many of these were actually aimed at children yet they were released outside of the holiday period. One of the reasons could be that because of tougher competition between releases during the holiday period, studios could actually be strategically positioning their releases so as not to compete with other major releases during the same time. Another explanation could be that during holidays children frequent the films more, therefore to smooth the seasonality and peaks during the holiday periods studios place other films outside the holiday period.

Contrary to these results, Litman (1983) reported a positive relationship between Christmas releases and revenue, citing that a film released during the Christmas period would earn \$10 million more than a film released during any other time of the year. Sochay (1994) reported a positive relationship between summer releases and revenue. Radas and Shugun (1998) also reported better performance at the box office for peak season releases. Einav (2001) also supported the view of better performance for summer and Christmas releases. The contrarian result for this variable in the current research could be because the dependent variable is global revenue whilst in all the other studies, the dependent variable was limited to USA domestic revenue only. The patterns of audience attendance may be different in the international markets. In the southern hemisphere, summer holidays are not in the June - August period and are shorter than in the US.

\section{Critical acclaim}

Surprisingly in this model, positive critical reviews did not display any linear relationship with revenue. In the data set of the top twenty grossing films, the average critic score was 63,95 . The highest critical acclaim was for the film The Social Network with a score of 95, which grossed \$ 224 million in revenue. The critic score for Avatar which grossed $\$ 2,7$ billion was 83 . Of the top 20 films the data set in terms of critic score, 16 received Academy Award nominations. There were certain anomalies in the sample. The film The Last Airbender scored only 20 in critic reviews, yet grossed $\$ 319$ million. Similarly, Sex and the 
City and Little Fockers 2 both scored 27 in critical acclaim yet grossed \$294 million and \$310 million respectively. The films The Damned United and The Secret of Kells were both highly critically acclaimed with a score of 81 each, yet earned only $\$ 4$ million and $\$ 2$ million respectively at the box office.

The results of this model were contrary to the results of other researchers. According to Litman, each additional star rating (used as a proxy for positive critics reviews), increased revenue by $\$ 3,3$ million. Litman contends that critics were perfect judges of quality of films, and that this variable may simply be measuring the differential effects of quality on revenue. According to Terry et al. (2005), a ten per cent increase in critical approval rating implied an increase in revenue of $\$ 7$ million. They proposed that films earning critical acclaim appeared to profit from the information cascade put forth by the positive word of mouth. They further propose that studios and distributors with negative critical reviews could cut their losses early by limiting their advertising campaigns and costs after release and speeding up the video release. Based on the results of their study they were of the opinion that critics were more predictors than influencers of box office revenue. They suggested that although reviews themselves could influence some filmgoers, the reviews primarily produced valuable predictive information about the ultimate success, or a film based on the film quality. According to them, many studios or distributors assume that critics are influencers and attempt to persuade critics to be favourable. They cited the example of Sony Pictures who created a fake film critic to positively review their releases, implying that insiders believed that film critics were important to box office success.

\section{Drama genre}

The results showed a negative relationship between the drama genre and revenue. The drama genre was included because of all the films in the data set, most were in the drama genre. Eighty-one films or 28 per cent were in the drama genre. In the data set drama films had the highest correlation with Academy Award nominations, however the market may be saturated with drama scripts, and the audience thus preferring to attend other genres of film resulting in higher revenues for the other genres. These results are consistent with Prag and Casavant (1994) who also reported a negative relationship for the drama genre and box office revenue. Sawnhey and Eliashberg (1996) reported that audiences react slower to the drama genre.

In summary it was found that approximately 64,8 per cent of the variation in revenue was explained by the model. A twotailed test was then performed on each independent variable to determine whether sufficient evidence existed to infer a linear relationship between the variable and revenue. It was found that only production cost, major studio release, academy award nomination, and the sequel variables had highly significant linear relationships with revenue. These results were then compared to the results of other authors. In certain cases the results of this study concurred with existing literature and in other cases the results were contrary to existing literature.

\section{Conclusion}

The main purpose of this research was to establish which factors, if any, contribute to the success of films at the box office. Using a multiple regression model, a number of variables believed to influence box office success were evaluated. The model's coefficient of determination, $\mathrm{R}^{2}$ was at 0,647 , overall significant.

The most significant contributor to box office revenue was found to be production cost. The model implied that higher production budgets would lead to higher global box office revenue. This result was consistent with three studies, Litman (1983), Ravid (1999), and Terry et al. (2005). Only one study showed no evidence of a positive relationship between the production cost variable and revenue (De Vany $\&$ Walls 1999). There were certain anomalies though, in that certain low budget films actually performed very well at the box office.

The results also showed that a release by a major studio had a positive relationship with revenue. Only one other study (Litman 1983) focussed on this variable and his conclusion was consistent with the result of this model. According to this model, films released by a major studio were expected to earn $\$ 11,3$ million more in revenue than films not released by a major studio.

Another significant contributor to box office success was award nominations. This model valued an award nomination at $\$ 39$ million. The positive relationship between award nomination and revenue was also confirmed by Litman (1983), Dodds and Holbrook (1988), Terry et al. (2005), and Nelson et al. (2001).

The other significant contributor to box office success identified by this model was sequel. The model revealed an overwhelmingly significant relationship between sequels and box office revenue. The result for sequel implied that a sequel could add as much as $\$ 169$ million to box office revenue. These findings were consistent with that of Terry $e t$ al. (2005), and Sombunarasin (2010) who found a positive and statistically significant relationship between sequels and box office revenue.

Two variables, action and drama, displayed insignificant negative coefficients. This was consistent with Anast (1967) whose study also showed a negative relationship between the action genre and revenue. Prag and Casavant (1994) showed a negative relationship for drama and revenue. Contrary to the result of this model, Terry et al. (2005), demonstrated a positive relationship between the action genre and revenue.

The results of the model showed that there was no significant relationship between a holiday release and revenue. This was contrary to the evidence presented by other researchers who all reported a positive relationship between a holiday release and revenue.

The critic variable surprisingly did not show any linear relationship with revenue. This was contrary to all other literature surveyed regarding the power of critic's reviews. 
All the other authors reported a positive relationship between critic reviews and revenue. The difference between this model and their studies could be due to the revenue variable in this sample being much wider than just covering the USA market. The critics' scores in this model were derived from USA critics only. If data was available for foreign critics in those markets outside the USA, the critical review ratings could possibly have increased.

The purpose of this was to identify and confirm the significance of various explanatory variables in forecasting global box office revenue of films using global box office revenue. It is concluded that the factors contribute to box office success, are films with higher budgets, released by a major studio, with one or more Academy nominations, and a sequel to a prior success. The significance of these statistical findings is supported by the literature.

Some directions for future research arise. It will be of interest to examine actual returns on investment as direct measure of the profitability of films. Complete production cost data, however, is difficult to obtain. In the present instance, the original sample of 1263 films had to be filtered down to 289 due to production cost data being unavailable. It would also be interesting to repeat the study using income data beyond ticket sales, e.g. income deriving from DVD sales, Blue-Ray sales and rentals, digital downloads, cable and satellite television and merchandising. Accurate supplementary data sources, however, remain problematic to access. Finally, incorporating income foregone through piracy may add a further dimension to studies regarding film investment.

\section{References}

AMPAS. 2012.' Resources and databases' [online] URL:http://www.oscars.org. Accessed: 19 January 2012.

Anast, P. 1967. 'Differential movie appeals as correlates of attendance', Journalism Quarterly, 44: 86-90.

Austin, B.A. 1984. 'Portrait of an art film audience', Journal of Communication, 34(winter): 74-87.

Box Office Mojo. 2012. 'Worlwide grosses'. [online] URL: http://www.boxofficemojo.com/alltime/world/ .Accessed: 11 January 2012.

De Vany, A. \& Walls, W.D. 1999. 'Uncertainty in the movie industry: Does star power reduce the terror of the box office?' Journal of Cultural Economics, 23: 285-318.

De Vany, A. \& Walls, W.D. 2002. 'Does Hollywood make too many R-rated movies? Risk, stochastic dominance, and the illusion of expectation', The Journal of Business, 75(3): 425-451.

De Vany, A. \& Walls, W.D. 2004. 'Motion picture profit, the stable Paretian hypothesis, and the curse of the superstar', Journal of Economic Dynamics \& Control, 28: 1035-1057.
Dodds, J.C. \& Holbrook, M.B. 1988. 'What's an Oscar worth? An empirical estimation of the effect of nominations and awards on movie distribution and revenues', Current Research in Film: Audiences, Economics and the Law, 4: 72-87.

Einav, L. 2001. 'Seasonality and competition in time: An empirical analysis of release date decisions in the U.S. motion picture industry'. Working Paper, Harvard University.

Eliashberg, J. \& Shugan, S.M. 1997. 'Film critics: Influencers or predictors?' Journal of Marketing, 61(2): 6878.

Litman, B. 1983. 'Predicting success of theatrical movies: An empirical study', Journal of Popular Culture, 16(spring): 159-175.

Metacritic. 2012. 'Metacritic - Keeping score of entertainment'. [online] URL: http://www.metacritic.com/. Accessed 19 January 2012.

Motion Picture Association of America (MPAA). 2011. The economic contribution of the motion pPicture \& television industry to the United States. Washington D.C: MPAA.

Neelamegham, R. \& Chinatagunta, P. 1999. 'A Bayesian model to forecast new product performance in domestic and international markets', Marketing Science, 18(2): 115-136.

Nelson, R., Donahue, M., Waldman, D. \& Wheaton, C. 2001. 'What's an Oscar worth?' Economic Inquiry, 39(1): 16.

OpusData. 2011. 'OpusData.' [online] URL:http://www.opusdata.com/. Accessed 20 December 2011.

Prag, J.J. \& Casavant, J. 1994. 'An empirical study of the determinants of revenues and marketing expenditure in the motion picture industry', Journal of Cultural Economics, 18(3): 217-235.

Radas, S. \& Shugan, S.M. 1998. 'Seasonal marketing and timing introductions', Journal of Marketing Research, 35(3): 296-315.

Ravid, S.A. 1999. 'Information, blockbusters, and stars: a study of the film industry', Journal of Business, 72(4): 463492.

Reddy, S.K., Swaminathan, V. \& Motley, C.M. 1998. 'Exploring the determinants of Broadway show success', Journal of Marketing Research, 35(3): 370-383.

Reinstein, D. A. \& Snyder, C.M. 2000. 'The influence of expert reviews on consumer demand for experience goods: A case study of movie critics'. Working Paper, University of California-Berkeley and George Washington University. 
Sawhney, M.S. \& Eliashberg, J. 1996. 'A parsimonius model for forecasting gross box-office revenues of motion pictures', Marketing Science, 15(2): 113-131.

Sedgwick, J. \& Pokorny, M. 1999. 'Movie stars and the distribution of financially successful films in the motion picture industry', Journal of Cultural Economics, 23: 319323.

Smith, S.P. \& Smith, V.K. 1986. 'Successful movies - a preliminary empirical analysis', Applied Economics, 18(May): 501-507.

Sochay, S. 1994. 'Predicting the performance of motion pictures', The Journal of Media Economics, 7(4): 1-20.

Somburanasin, M. 2010. 'Risky business: Does recognition reduce uncertainty of the movie industry global box office revenue?' Master thesis within Economic and Management of Entertainment \& Arts, Jonkoping International Business School, Jonkoping University, Sweden.

Terry, N., Butler, M. \& De'Armond, D. 2005. 'The determinants of domestic box office performance in the motion picture industry', Southwestern Economic Review, 32: 137-148.

The Numbers. 'Pulp fiction'. [online] URL: http://www.thenumbers.com/movies/1994/0PUFI.php. Accessed 17 January 2012.

Wallace, W.T., Seigerman, A. \& Holbrook, M.B. 1993. 'The role of actors and actresses in the success of films: How much is a movie star worth?' Journal of Cultural Economics, 17(1): 1-27. 